\title{
Closure of Refractory Gastrocutaneous Fistula Using Endoclipping
}

Percutaneous endoscopic gastrostomy (PEG) plays an important role in maintaining enteral nutrition in patients with swallowing disorders. After placement of a PEG tube, a gastrocutaneous fistula forms. This fistula usually resolves without therapy after gastrostomy tube removal. We report the case of a patient who developed a refractory gastrocutaneous fistula, after PEG tube removal, that was successfully closed using endoclips.

A 57-year-old man was referred to us for PEG placement after surgery followed by radiotherapy for a laryngeal tumor. After 2 years the patient no longer had swallowing difficulties and the PEG tube was removed. At 2 months later, the gastrocutaneous fistula had not closed spontaneously, and gastric content leaked through the fistula causing skin excoriation around the cutaneous orifice. An upper gastrointestinal endoscopy was performed and the gastric side of the fistula was identified (Figure 1). On instillation of water with a catheter through the opening of the fistula on the gastric side, water was seen to leak out on the cutaneous side. Three endoclips (Quick Clip HX-200V-135; Olympus, Hamburg, Germany) were applied to grasp the margins of the orifice (Figure 2 ). Immediate instillation of water through the cutaneous side of the fistula after closure with endoclips showed no further leakage. The patient was treated for 1 week with parenteral nutrition, intravenous proton pump inhibitor, and subcutaneous octreotide to decrease gastric secretion. An endoscopy was then performed that showed closure of the orifice, without leakage after instillation of water. Oral intake was resumed successfully and parenteral nutrition was discontinued. At the 6-week follow-up, examination showed complete healing of the fistula site.

Refractory gastrocutaneous fistula is a rare complication of PEG insertion [1]. A nonhealing gastrocutaneous fistula usually requires surgical closure of the fis-

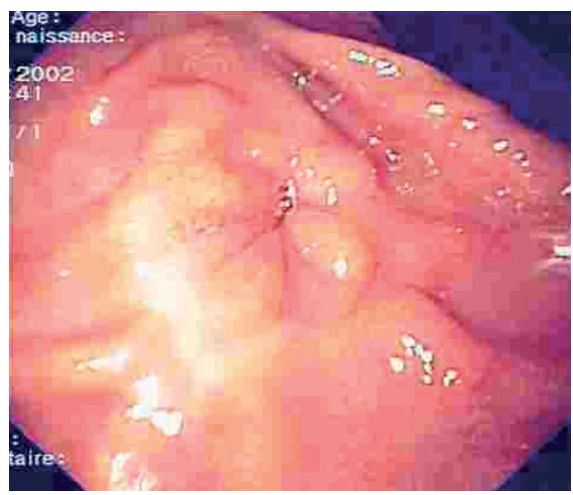

Figure 1 Endoscopic view showing the gastric side of the gastrocutaneous fistula.

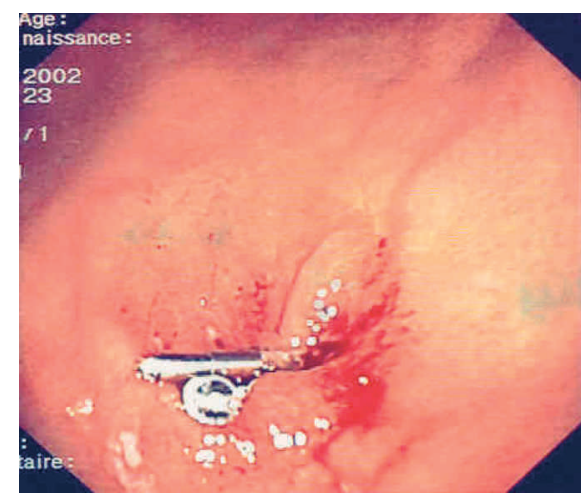

Figure 2 Endoscopic view showing endoclipping applied to the margins of the orifice of the gastrocutaneous fistula.

tula track [2]. There have been isolated reports of successful endoscopic treatment, including endoscopic injection of a fibrin sealant [3], injection of biological fibrin glue after endoscopic location of the fistula [4], and percutaneous endoscopic suturing [5]. To our knowledge, this is the first report of the use of endoclips for closing a nonhealing gastrocutaneous fistula after PEG tube removal. This technique should be considered, especially in high surgical risk patients.

\section{A. Chryssostalis, I. Rosa, G. Pileire,} V. Ozenne, M. Chousterman, H. Hagège

Division of Gastroenterology, Centre Hospitalier Intercommunal de Créteil, Créteil, France

\section{References}

${ }^{1}$ Schapiro GD, Edmundowicz SA. Complications of percutaneous endoscopic gastrostomy. Gastrointest Endosc Clin N Am 1996; 6: 409-422

2 Bender JS, Levison MA. Complications after percutaneous endoscopic gastrostomy removal. Surg Laparosc Endosc 1991; $1: 101-103$

${ }^{3}$ Shand A, Pendlebury J, Reading Set al. Endoscopic fibrin sealant injection: a novel method of closing a refractory gastrocutaneous fistula. Gastrointest Endosc 1997; 46: 357 - 358

${ }^{4}$ Rabago LR, Ventosa N, Castro JLet al. Endoscopic treatment of postoperative fistulas resistant to conservative management using biological fibrin glue. Endoscopy 2002; 34: 632-638

${ }^{5}$ Devereaux CE, Binmoeller KF. Endoclip: closing the surgical gap. Gastrointest Endosc 1999; 50: 440-442

\section{Corresponding Author}

\section{H. Hagège, M.D.}

Centre Hospitalier Intercommunal de

Créteil

40 avenue de Verdun

94000 Créteil

France

Fax: $\quad+33-1-45175476$

E-mail: herve.hagege@chicreteil.fr 